\title{
Güneydoğu Anadolu'da Kırmızı Mercimekte (L. culinaris Medik.) Pazarlama Fiyatını Düşüren Bazı Değerleme Faktörlerinin İncelenmesi
}

\author{
*Irfan ÖZBERK
}

Ömer Faruk TANRIKULU²

\author{
${ }^{1}$ Harran Üniversitesi Ziraat Fakültesi Tarla Bitkileri Bölümü, Şanlıurfa \\ ${ }^{2}$ Kocaköy İlçe Gıda Tarım ve Hayvancılık Müdürlüğü, Diyarbakır \\ *Sorumlu yazar e-posta (Corresponding author; e-mail):ozberki@harran.edu.tr
}

Geliş Tarihi (Received): 08.01.2014

Kabul Tarihi (Accepted): 22.03.2014

Öz

$\mathrm{Bu}$ çalışmada mercimekte borsa pazarlama fiyatlarını düşüren tebeşirleşmiş taneler, Arap baklası (Vaccaria primidata Med.), Dilkanatan (Galium aperine), yabani yulaf (Avena fatua L.) ve bunların karışımlarından oluşan selektör altı safsızlığın etkileri araştırılmıştır. Yerli kırmızı saf mercimek tohumluğuna $\% 3,6,9,12$ ve 15 oranlarında eklenen fiyat değerleme faktörlerinden oluşan örnekler Şanlıurfa ve Diyarbakır yerel borsalarında tesadüfen seçilen 4 mercimek alıcılarına (tekerrür) sunulmuş ve fiyat tahminleri alınmıştır. Yapılan varyans analizlerinin tümünde karışım oranları istatistiksel olarak önemli bulunmuş, tebeşirleşmiş tanelerin oranının artmasının pazarlama fiyatını düşüren en önemli değerlendirme faktörü olduğu belirlenmiştir. Buna karşın yabani yulaf tohumlarının mercimeğe karışımlarının pazarlama fiyatlarının düşmesine en az etkisi olan faktör olduğu anlaşılmıştır. Karışım oranlarıyla pazarlama fiyatları arasındaki ilişkiler regresyon analizi yoluyla incelenmiş; tüm faktörler istatistiksel olarak önemli bulunurken, elde edilen eşitliklerin yüksek determinasyon katsayıları $\left(\% R^{2}\right)$ bu eşitliklerin bölgede mercimek fiyat tahminlerinde kullanılabileceği anlaşılmıştır. Sonuç olarak tebeşirleşmeye neden olan zararlı böcekler ve geniş yapraklı yabancı otlarla mücadelenin kaçınılmaz olduğu, bu çeşit değerleme faktörleri için işleme, pazarlama ve dış satımda yer alan paydaşların bir araya gelerek ortak standartlar belirlemesi gerektiği tespit edilmiştir.

Anahtar Kelimeler: Mercimek, değerleme faktörleri ve pazarlama fiyatları ilişkileri

\section{A Study on Some Grading Factors Affecting Marketing Price of Red Lentil (L. culinaris Medik.) in South- East Anatolia}

\begin{abstract}
In this work, it was studied the effects of chalky grains, cow basil (Vaccaria primidata Med.), cleavers (Galium aperine), common wild oat (Avena fatua L.) and selector output impurity on to marketing price of lentil. The samples consisting of grading factors added to the land race red lentil seed in the ratio of 3, 6, 9, 12 and $15 \%$ were presented to four (4) incidentally selected lentil-purchasers from Sanliurfa and Diyarbakir local commodity market and, the price estimations were obtained. In all of variance analysis, it was found that the mixture ratios had a statistical importance, that the increasing ratio of chalky grains is the most important grading factor, whereas common wild oat seeds in lentil was, on the contrary, the least affecting factor on to marketing price. The relations between mixture ratios and marketing prices were studied by regression analysis; regression was found to be statistically significant for all the factors where the high coefficients of determination $\left(\% \mathrm{R}^{2}\right)$ indicated that these equations can be used in the sense of estimating the price in the region. The results showed that it is inevitable to struggle against insect pests and latifolius (broadleafed) weed. The stakeholders involved in processing, marketing and exportation should determine the common standards for such grading factors.
\end{abstract}

Keywords: Lentil, grading factors and marketing prices relation

\section{Giriş}

$\mathrm{M}$ ercimek (Lens culinaris Medik.) \% 75 karbonhidrat, \% 21 protein ve \% 4 yağ içeriği ile yüksek enerji ve protein kaynağı bir besin olup, thiamin, demir, fosfor ve bakır bakımından zengindir. Vitamin C bakımından da zengin olan mercimek, yüksek oranda folik asit içermesi bakımından da başta kalp hastalıklarının ve doğum bozukluklarının 
önlenmesinde oldukça önemlidir (Anonim, 2007; Anonim, 2008a; Coskuner ve Karababa 1998). Doymuş yağlar, kolesterol ve sodyum bakımından düşük değerlere sahip olan mercimek favogenler, oligosakkaritler ve hemagluteninler gibi besin dışı faktörler bakımından da düşük değerlere sahiptir (Coskuner ve Karababa 1998; Anonim 2007) Dünya genelinde çeşitli şekillerde tüketilmektedir. Hindistan'da kaynatılarak (dhal) veya pide şeklinde buğday veya mısır unuyla karıştırılmış olarak (ruti) tüketilmektedir. Khichri adı verilen yemeği de yapılmaktadır (Williams ve ark. 1993; Coskuner ve Karababa 1998). Ülkemizde ve Orta doğuda genellikle çorba olarak tüketilmektedir. Ayrıca mercimekli köftede, hazır çorbalarda ve mercimek unu yapımında kullanılmaktadır (Coskuner ve Karababa 1998).

2010 yılı itibarıyla Dünya yeşil+kırmızı mercimek ekim alanı 4.189.000 ha, üretimi 4.585.439 tondur. Ortalama verim ise 110 kg/da'dır. 2004-2009 yılları arasında ekim, üretim ve verim değerleri stabil görülmektedir (Anonim 2012a).Kanada, Hindistan, Türkiye, $A B D$, Nepal ve Avustralya sırasıyla üretimde ilk sıralarda yer almaktadırlar. Kanada, ABD, Türkiye ve Avustralya sırasıyla en büyük dış satımcı ülkelerdir (Anonim 2012a).

Ülkemizin 2012 itibarıyla kırmızı mercimek ekim alanı 214.787 ha ve üretimi 410.000 tondur. Ortalama verim ise $191 \mathrm{~kg} / \mathrm{da}$ 'dır (Anonim 2012b). Mercimek ekim alanı ve üretimde son 20 yılda bir düşüş gözlenirken verimde yaklaşık 20 kg/da'lık bir artış söz konusudur.

Güneydoğu Anadolu bölgesi ülkemizin kırmızı mercimek kuşağı olarak bilinmektedir. Yerli kırmızı gibi yerel çeşitler, Fırat-87 (Komando), Seyran-96 ve Çağıl gibi kültür çeşitler bölgede yaygın olarak ekilmektedir.

Güneydoğu Anadolu Bölgesi mercimek hastalık ve zararlıları ve parazitik ve parazitik olmayan geniş yapraklı yabancı otlar bakımından da önemli bir çeşitliği barındırmaktadır. Apion [Apion arrogans Wenck. (Coleoptera, Curculionidae)], mercimek hortumlu böceği [Sitona crinitus Herbst.(Col.:Curculionidae)], nohut yeşil kurdu [Heliothis viriplaca (Hufn.) (Lep.: Noctuidae)], dut kımılı [Dolycoris baccarum L. (Hemiptera: Pentatomidae)], lygus böceği [Exolygus pratensis (H.-S.) (Hemiptera: Miridae], gibi zararlılar, canavar otu [Orobanche
spp.Orobanchaeae], gibi parazitik bitkiler, kök boğazı çürüklüğü (Ascochyta pinodella Jones) ve mildiyö (Peronospora lentils) gibi hastalıklar en önemli verim sınırlayıcı faktörlerdir (Uzun 1992; Zel 1974; Anonim 2013a; Anonim 2013b; Anonim 2013c; Anonim 2010).

Özellikle verimde \% 100'e varan oranda düşüşe neden olan canavar otu ve ürün kalitesini (tebeşirleşme) ve dolayısıyla pazarlama fiyatını çok düşüren dut kımılı büyük önem arz etmektedir. Ürün işleme sırasında selektörlerden benzer tane büyüklüğü ve tohum çengeli nedeniyle ayrılamayan Arap baklası (Vaccaria pyramidata Med.) ve Dilkanatan (Galiumaperine) tohumlarının da ürüne karışması halinde pazarlama fiyatını düşürdükleri ve birim alana düşen net geliri azalttıkları anlaşılmıştır.

Ülkemizde mercimek işleme süreci Hindistan ve Suriye ile benzer olarak; temizleme, yıkama, kurutma, tavlama ve sınıflama (tane boyutuna göre), kabuk soyma, parlatma ve yarma şeklinde olmaktadır (Coskuner ve Karababa 1998).

Mercimek işleyen tesislerin verimliliğini etkileyen faktörler; ürün içindeki yabancı materyal, ürünün tane boyutu, tanenin şekli, tanenin yapısı (kırık tane oluşumu), tane kabuk kalınlığı, kurutma-tavlatma uygulamaları, depolama koşulları, depo mantar ve zararlıları olarak sayılabilir (Coskuner ve Karababa 1998).

En önemli kırmızı mercimek üreticileri ve ihracatçıları olan Kanada, ABD ve Avustralya ile en önemli tüketici ülkelerden olan Hindistanda mercimek dış satımı/alımı ile ilgili çok sıkı kurallar uygulanmaktadır.

Ülkemizde ise kırmız mercimekler kabuklu mercimek ve kırmızı iç mercimek olarak 2 sınıfa ayrılmıştır. Her iki grup da kendi içlerinde \% nem, toplam yabancı madde varlığı, \% inorganik madde varlığı, toplam kusurlu tane varlığı, böcek hasarlı tane varlığı, kızışmışçimlenmiş tane varlığı, kırık-kabuğu soyulmuş tane varlığı, iç mercimekte kabuğu soyulmamış tane varlığı gibi faktörler dikkate alınarak dikkate alınarak sınıf 1 ve sınıf 2 olarak alt gruplara ayrılmıştır (Anonim 2008a).

Ülkeden ülkeye değişen kırmızı mercimek standartlarının oluşumunda çiftçiden yerel borsalara/alıcı tüccarlara gelen ürünün temizliği büyük önem taşımaktadır. Aksi halde işleme süreci masrafları işletmelere ağır yükler getirmektedir. 
Bu çalışmada kabuklu kırmızı mercimek ürününde pazarlama fiyatını düşüren safsızlık yaratan bazı kıymetlendirme (değerleme) faktörlerinin pazarlama fiyatlarına olan olumsuz etkileri araştırılacak ve ürünün değeri fiyata satışını sağlamak için tüm paydaşların üzerine düşen görevler belirlenecektir.

\section{Materyal ve Yöntem}

Şanlıurfa ve Diyarbakır yerel ürün borsalarında yapılan ön etüt sonucunda mercimekte çiftçilerden alınan üründe fiyatı düşüren en önemli faktörler; tebeşirleşmiş taneler, mercimek içinde yabani bakla (Arap baklası), çengelli dil kanatan tohumları ile sap, kavuz, diğer yabancı ot tohumları vs. den oluşan selektör altı denilen karışım olduğu anlaşılmıştır.

Viranşehir bölgesi 2013 ürünü olan kabuklu yerli kırmızı mercimek dokaj'dan geçirildikten sonra laboratuarda aşağıda belirtilen toplam 100 g'lık örnekler hazırlanmıştır;

A: Tebeşirleşmiş taneler (A6: $100 \mathrm{~g} \% 100$ saf mercimek; A5: \%97 + \%3 tebeşirleşmiş daneler TD); A4: \%94 + \%6 TD; A3: $\% 91+$ \%9TD; A2: \%88 + \%12TD; A1: \%85 + \%15TD)

B: Yabani bakla taneleri (B6 : 100g \% 100 saf mercimek; B5 : \%97+\%3 yabani bakla (YB); B4 : $\% 94+\% 6 Y B ; \quad B 3: \% 91+\% 9 Y B ; \quad B 2:$ $\% 88+\% 12$ YB; B1 : $\% 85+\% 15 Y B$ )

C: Dilkanatan tohumları (C6:100g \% 100 saf mercimek; C5 : \%97+\%3 dil kanatan (DK); C4 : \%94+\%6DK; C3 : \%91+\%9DK; C2: \%88+\%12DK; C1 : \%85+\%15DK)

D: Yabani yulaf tohumu (D6: 100g \% 100 saf mercimek; D5 : \%97+\%3 yabani yulaf (YY); D4 : \%94+\%6YY; D3 : \%91+\%9YY; D2: $\% 88+\% 12$ YY; D1 : $\% 85+\% 15 Y Y$ )
E: Tüm elek altı materyal (E6 : 100g \% 100 saf mercimek; E5 : \%97+\%3(tüm elek altı (TEA); E4 : \%94+\%6TEA; E3 : \%91+\%9TEA; E2: \%88+\%12TEA; E1 : \%85+\%15TEA)

Hazırlanan örnekler 4 ve 29 Eylül 2013 tarihlerinde sırasıyla Şanlıurfa ve Diyarbakır borsalarında tesadüfen seçilen 4'er mercimek alıcısına sunularak fiyat tahminleri alınmıştır.

Pazar fiyatları varyans analizine (TB 4 tekerrürlü) tabi tutulmuş, fiyat ortalamaları LSD testine göre gruplanmıştır. Her iki lokasyondaki denemelerden elde edilen hata varyansları $F$ testiyle karşılaştırılmıştır. Böylece birleşik varyans analizi yapma olasılığı test edilmiştir. Denemeye konu olan faktörlerin tüm karışım oranlarıyla Pazar fiyatı ilişkileri regresyon analizine tabi tutulmuş ve elde edilen eşitliklerin fiyat tahminlemede kullanılma olasılığı araştırılmıştır.

\section{Bulgular ve Tartışma}

Şanlıurfa borsasından alınan verilerin varyans analizinde tüm faktörlere ait oranlar istatistiksel olarak önemli bulunmuştur (F Tebeşirleşmiş daneler: 128.39***, F Yabani bakla taneleri: $48.01^{* * *}$, F Dil kanatan tohumları: $110.73^{* * *}, \mathrm{~F}$ Yabani yulaf tohumu: $3.38^{* *}$, F Tüm elek altı materyal: $125.43^{* * *}$ ).

Şanlıurfa'da yürütülen çalışmada tüm faktörlere ait safsızlık oranlarına göre oluşan Pazar fiyatları LSD testine göre gruplanmış, gruplar çizelge 1 de verilmiştir.

Buna göre saf mercimek içinde tebeşirleşmiş taneler arttıkça fiyat düşüşlerinin hızlı olduğu, ancak yabani yulaf tohumlarının safsızlığı artırması halinde pazar fiyatlarındaki düşmenin diğer karışımdaki düşmelere göre en az olduğu tespit edilmiştir. Yabani bakla ve dilkanatan tohumlarının artan oranlarının yaptığı safsızığın fiyat değerlemesinde tebeşirleşmeyi takip ettikleri anlaşılmıştır.

Çizelge 1. Şanlıurfa borsasında çeşitli değerleme faktörlerine göre oluşan pazar fiyatları (Kr/kg) ve ‘En Küçük Önemli Farklılık testi' grupları

Table 1. Marketing prices $(\mathrm{Kr} / \mathrm{kg})$ and LSD groups formed on Sanliurfa Stock Market Exchange according to various grading factors

\begin{tabular}{cccccc}
\hline Karışım oranları & Faktör A Grup & Faktör B Grup & Faktör C Grup & Faktör D Grup & Faktör E Grup \\
\hline A6 \%0 & $148.00 \mathrm{a}$ & $147.50 \mathrm{a}$ & $149.25 \mathrm{a}$ & $150.50 \mathrm{a}$ & $148.75 \mathrm{a}$ \\
A5 \%3 & $144.00 \mathrm{~b}$ & $143.75 \mathrm{ab}$ & $143.50 \mathrm{~b}$ & $147.50 \mathrm{~b}$ & $144.75 \mathrm{~b}$ \\
A4 \%6 & $141.25 \mathrm{~b}$ & $141.50 \mathrm{~b}$ & $142.25 \mathrm{~b}$ & $146.00 \mathrm{bc}$ & $143.00 \mathrm{c}$ \\
A3 \%9 & $124.50 \mathrm{c}$ & $134.75 \mathrm{c}$ & $133.75 \mathrm{c}$ & $144.50 \mathrm{c}$ & $136.75 \mathrm{~d}$ \\
A2 \%12 & $124.50 \mathrm{c}$ & $129.00 \mathrm{~d}$ & $133.50 \mathrm{c}$ & $141.50 \mathrm{~d}$ & $133.50 \mathrm{e}$ \\
A1 \%15 & $119.75 \mathrm{~d}$ & $125.25 \mathrm{~d}$ & $130.50 \mathrm{~d}$ & $137.25 \mathrm{e}$ & $131.00 \mathrm{f}$ \\
\hline
\end{tabular}


Çizelge 2. Diyarbakır borsasında çeşitli değerleme faktörlerine göre oluşan pazar fiyatları ve gruplar Table 2. Marketing prices and groups formed on Diyarbakir Stock Market Exchange according to various valuation factors

\begin{tabular}{cccccc}
\hline Karışım oranları & Faktör A grup & Faktör B Grup & Faktör C Grup & Faktör D Grup & Faktör E Grup \\
\hline A6 \%0 & $127.00 \mathrm{a}$ & $127.50 \mathrm{a}$ & $126.12 \mathrm{a}$ & $125.37 \mathrm{a}$ & $127.00 \mathrm{a}$ \\
A5 \%3 & $123.75 \mathrm{a}$ & $125.00 \mathrm{a}$ & $120.50 \mathrm{~b}$ & $123.62 \mathrm{a}$ & $123.75 \mathrm{a}$ \\
A4 \%6 & $121.75 \mathrm{~b}$ & $123.75 \mathrm{a}$ & $120.37 \mathrm{~b}$ & $121.25 \mathrm{a}$ & $120.50 \mathrm{ab}$ \\
A3 \%9 & $119.00 \mathrm{~b}$ & $120.25 \mathrm{~b}$ & $116.25 \mathrm{~b}$ & $113.12 \mathrm{~b}$ & $116.50 \mathrm{~b}$ \\
A2 \%12 & $117.75 \mathrm{~b}$ & $118.50 \mathrm{~b}$ & $112.50 \mathrm{bc}$ & $112.75 \mathrm{~b}$ & $116.25 \mathrm{~b}$ \\
A1 \%15 & $103.12 \mathrm{c}$ & $113.50 \mathrm{~b}$ & $109.25 \mathrm{bc}$ & $109.37 \mathrm{~b}$ & $113.25 \mathrm{bc}$ \\
\hline
\end{tabular}

Diyarbakır borsasında yürütülen çalışmada tüm faktörlere ait safsızlık oranları istatiksel önemde bulunmuş ( FA: 23.76*** FB: 4.52**, FC: $11.46^{* * *}$, FD: $7.76^{* * *}$, FE: $5.64^{* *}$ ) LSD testine göre gruplanmış ve sonuçlar Çizelge 2 de verilmiştir.

Yapılan varyans analizinde Diyarbakır borsasında mercimekte Pazar fiyatını düşüren değerleme faktörlerinin tebeşirleşme olduğu bunu yabani yulaf ve dilkanatan faktörlerinin izlediği, elek altı ve yabani baklanın dramatik fiyat düşmelerine neden olmadığı anlaşılmıştır. Her iki lokasyonda yürütülen çalışmalardan elde edilen hata kareler ortalaması $F$ testiyle karşılaştırılmış varyansların homojen olmadığı anlaşıldığı için birleşik Varyans Analiz Tablosu (VAT) yapılmamıştır.

Regresyon analizleri: Çeşitli değerleme faktörlerinin üzerinde çalışılan oranlarıyla pazar fiyatları arası ilişkiler regresyon analiziyle daha detaylı araştırılmış ve sonuçlar Çizelge 3'te verilmiştir.

Her iki lokasyonda da değerleme faktörleriyle pazar fiyatları arasında istatiksel önemde negatif korelasyon ilişkileri tespit edilmiş, regresyonlar istatiksel olarak önemli bulunmuş, bulunan regresyon eşitlikleri yüksek determinasyon katsayısı $\left(R^{2}\right)$ değerleri vermişlerdir.

Her iki borsada da alıcılarla yapılan görüşmelerde her türlü safsızlık yaratan fiyat değerleme faktörünün \%6'ya kadar olmasının tolere edildiği \%6'ık safsızlığa verilen fiyatın baz fiyat olduğu \%6'dan az olan safsızlıkların üreticiye pirim, \%6'dan fazla safsızlıkların her \%1'i için o günkü pazar fiyatının \%1'i kadar (Örneğin 1,40 Kr/kg fiyat varsa, \%7 safsızlığa sahip ürün fiyatı $1,40-0,14=1,26 \mathrm{Kr} / \mathrm{kg}$ ) bir miktar ceza olarak üreticiye yansımaktadır. Pirimlendirmede de aynı yol izlenmektedir. Viranşehir orijinli koyu kırmızı kahve renkli yerli kırmızı mercimeğe Şanlıurfa borsasında Diyarbakır borsasına göre daha yüksek Pazar fiyatı önerilmiştir. Koyu kırmızı renk mercimek en kaliteli sayılırken (Coşkuner ve Karababa 1998) Diyarbakır'da daha açık kabuk renkli mercimeklere daha yüksek pazar fiyatı önerildiği anlaşılmış, alıcıların bildikleri mercimek dışında mercimek alımında tereddütlü davrandıkları anlaşılmıştır.

Çizelge 3. Şanlıurfa ve Diyarbakır borsalarında değerleme faktörlerinin çeşitli oranlarıyla pazar fiyatları arası korelasyon/regresyon ilişkisi

Table 3. The relation between various rates of valuation factors and correlation/regression on Sanliurfa and Diyarbakir stock market exchange

\begin{tabular}{|c|c|c|c|c|c|}
\hline Lokasyon & Faktör & Reg F & Reg Eşitliği & $\begin{array}{c}\text { Korelasyon } \\
(r)\end{array}$ & $\begin{array}{l}\text { Determinasyon } \\
\text { Katsayısı }\left(\% R^{2}\right)\end{array}$ \\
\hline \multirow{5}{*}{ Şanlıurfa } & $A$ & $43.30^{* *}$ & $y=149.13^{* *}-2.062^{* *} x$ & $-0.957^{\star *}$ & 91.5 \\
\hline & B & $211.73^{\star * \star}$ & $y=148.54^{* *}-1.545^{* *} x$ & $-0.991^{\star *}$ & 97.7 \\
\hline & C & $63.17^{* * *}$ & $y=148.23^{* *}-1.26^{* *} x$ & $-0.97^{\star *}$ & 92.6 \\
\hline & $\mathrm{D}$ & $111.79^{* \star *}$ & $y=150.41^{* *}-0.817^{* *} x$ & $-0.983^{* *}$ & 95.7 \\
\hline & $\mathrm{E}$ & $235.89^{\star * \star}$ & $y=149.2^{* *}-1.255^{* *} x$ & $-0.992^{* \star}$ & 97.9 \\
\hline \multirow{5}{*}{ Diyarbakır } & $A$ & $16.80^{*}$ & $y=128.73^{* *}-1.33^{*} x$ & $-0.898^{\star *}$ & 80.8 \\
\hline & B & $115.57^{\star *}$ & $y=128.06^{* \star \star}-0.886^{* \star \star} x$ & $-0.983^{* *}$ & 96.7 \\
\hline & $\mathrm{C}$ & $132.23^{\star \star \star}$ & $y=125.53^{* \star \star}-1.072^{* \star \star} x$ & $-0.985^{\star *}$ & 97.1 \\
\hline & $\mathrm{D}$ & $64.19^{* *}$ & $y=126.207^{* \star *}-1.15^{* *} x$ & $-0.97^{* *}$ & 94.1 \\
\hline & $E$ & $90.37^{* *}$ & $y=126.31^{* \star *}-0.902^{* \star} x$ & $-0.978^{\star *}$ & 95.8 \\
\hline
\end{tabular}


Şanlıurfa ve Diyarbakır borsalarında pazar fiyatlarını en fazla düşüren değerleme faktörünün tebeşirleşmiş taneler olduğu anlaşılmıştır. Alıcılar artan oranları gözle kolayca tespit edebilmelerine karşın Diyarbakır'da alımlarda 100 gr örneği elekten geçirme ve elek altının tartılması esasına göre fiyat belirlenmektedir. Şanlıurfa borsasındaki alıcılar gözle safsızlık tespitinde daha tecrübeli bulunmuşlardır. Bu yöndeki bulgular daha önce (Özberk ve ark, 2006) tarafından da tespit edilen bulgularla örtüşmektedir. Tebeşirleşmenin pazar fiyatına olan olumsuz etkileri araştırımış ancak diğer faktörlerle kıyaslanması bu çalışma da yapılmış ve fiyat düşüren en önemli faktör olduğu teyit edilmiştir. Şanlıurfa da üründe yabani bakla ve dilkanatan tohumları varlığı fiyat değerleme faktörü olarak 2.ve 3. Sırada yer alırken, Diyarbakır da yabani yulaf ve dil kanatan 2. ve 3. Sirada yer alması Diyarbakır bölgesinde Arap baklasının kayda değer yabancı ot olarak görülmediğini işaret etmektedir.

Arap baklası tanelerinin görünüm ve irilik olarak üründen selektörlemede kolay ayrılabilir olmaması fiyat düşürücü unsur olmasına neden olurken dilkanatan tohumları (ikiz-çengelli) üründen daha küçük ve yuvarlak olması nedeniyle eleklerden ayrılabileceği mümkün iken çengelleri yüzünden elekleri tıkamakta ve ürün içinde kalabilmektedir. Bu nedenle ürün market fiyatlarını dolayısıyla borsada üreticiden alım fiyatını düşürmektedir.

Tüm selektör altı her iki borsada da pazar fiyatlarını en çok düşürmesi beklenirken, orta derecede düşürmesi bu borsalarda selektör altının yem değerinin yüksek olması ve yem olarak satılıp (Anonim, 2013 e) artı değer yaratması mercimek ürün fiyatlarına daha az fiyat düşmesi olarak yansımaktadır.

Mercimekte geniş yapraklı yabancı ot kontrolünün değerlemede oldukça önemi olduğu görülmektedir. Özellikle yağışa dayalı koşullarda 1. yıl buğday-arpa, 2.yıl yemeklik tane baklagiller (mercimek-nohut) rotasyonunda 1. yıl geniş yapraklı ot kontrolü 2. yıl temiz tarla ve ürün için yaşamsal önemde bulunmuştur. Güneydoğu Anadolu da Diyarbakır, Şanlıurfa, Mardin, Elazığ ve Muş'ta hububat tarlasında tespit edilen 360 yabancı ot çeşidinin (Zel 1974) içinde yer alan yabancı otlardan dilkanatan, Arap baklası ve yabani yulaf (Zel 1974; Uzun 1992) mercimekte de pazar fiyatını düşüren en önemli değerleme faktörleri arasındadır. Mercimek içinde yabani yulaf fluazi fobbiltyl (\%
25) etkili maddeli ilaçlarla (Uzun, 1992) kontrol edilirken, mercimekte ekim öncesi uygulanan Imazethapyr (litrede $100 \mathrm{gr}$ ) etkili maddeli ilaçlarla kontrol edilebilir (Anonim 2013b).

Tebeşirleşme etmenleri dut kımılı (Dollycoris baccarum) baklagil pentatomidi (Prezedorus lituratus) (Anonim 2010) ve lypus böceği (Exolypus pratense)'dir. Dut kımılı kışı bitkiler altında geçirerek ilkbaharda ovalara inip geniş yapraklı otlarla beslenir. Mercimeğin çiçeklenme döneminde yapraklarına yumurta bırakan erginlerin yumurtalarından çıkan 2, 3. 4. ve 5. dönem nimfleri hasada kadar mercimek tanelerini kapsül üzerinden emerek beslenir. Danede emgiye maruz kalan yerler buğdayda süne emgisinde olduğu gibi krater görünümü alır ve kabuğu soyulduğunda tanenin bir bölümü tebeşir tozu gibi dağılır. Pazar değerini dramatik derecede düşüren bu zararlı yabancı ot mücadelesi yapılarak kontrol edilebilir.

Türkiye'de mercimek işleme teknolojisi: temizleme, boyutlandırma, kabuk soyma, yarma-iç mercimek üretimi ve cilalama işlemlerinden oluşmaktadır. İşleme verimliliğine etkin olan faktörlerden içindeki yabancı materyal oranı çiftçi düzeyinde kontrol edilebilecek unsurlardandır. Pestisit ve yabancı ot kontrolü ile üründeki yabancı madde miktarı azaltılabilir (Coskuner ve Karababa 1998).

Türk mercimek standartlarına göre kabuklu mercimekte yabancı madde oranı sınıf 1 için \% 3 sınıf 2 için \% 4 olarak belirlenirken iç mercimekte bu oran sınıf 1 için \% 0,5 ve sınıf 2 için \%1 olarak belirlenmiştir. Böcek hasarlı tane de kabuklu mercimek sınıf 1 de $\% 0,5$ ve sınıf 2 de $\% 1$ iken iç mercimekte hiçbir tolerans yoktur (Anonim 2008a).

Kanada kırmızı mercimek standartlarında kabuklu kırmızıda hiçbir yabancı ot tohumu varlığına izin verilmezken böcek zararlı taneler 4 sınıfta da \% 0,01'i aşamaz (Anonim 2013d).

ABD standartlarına göre ise \% 4'ten fazla böcek zararlı tane hiçbir sınıfa giremez (Anonim 2008b). Yabancı materyal (taşları da içeren) sınıf 1 için \% 0,2 2. ve 3. sınıf için \% 0,5'i aşamaz (Anonim 2008b).

Avustralya 1. sınıf kabuklu mercimek alım (çiftçiden) standartlarına göre ise yabancı materyal \% 3'ü aşamaz. Tarla böcekleri ise iki canlı veya 200 g'da en fazla 15 adet tolere edilir. Hindistan kabuklu Masoor mercimeği standartlarına göre yabancı madde special, standart ve General sınıflarında organik 
+ inorganik olarak \% 0,1, \% 0,6 $(0,5+0,1), \% 1$ $(0,75+0,25)$ 'i geçemez. Diğer yenilebilir tane varlığı da genel sınıfta bile \% 3'ü geçemez (ağırlıkta) (Anonim 2004).

Türk mercimek standartlarında mercimek içinde yabancı madde, tane nemi, inorganik maddeler, böcek hasarlı taneler, kızışmış + çimlenmiş taneler, kırık ve kabuğu soyulmamış taneler standardı oluşturan öğeler olurken Kanada renk, yabancı madde, lekeli taneler, çimlenmiş taneler, kırık taneler, olgunlaşmamış taneler, don zararlı taneler, antraknoz zararlı taneler standardı oluşturan başlıca öğelerdir. Avustralya çiftçiden alım ve dış satım standartlarında benzer unsurları dikkate almıştır. ABD standartları daha esnek olup, yine renk ön plandadır. Türk standartları gibi Hint standartlarında da renge öncelik verilmemiştir.

\section{Sonuç}

Ülkemizde mercimek tarımında çiftçilerin ve borsada alıcılar farklı değerleme faktörlerini dikkate alırken mercimek işleme teknolojisinin talep ettiği ürün niteliği farklıdır. İşlenen ürünün Türk standartlarına uyumunda da kıstaslar kısmen örtüşmektedir. Ancak standartları yakalamanın çiftçi düzeyinde başladığı düşünülerek mercimekte tebeşirleşme etmeni ve yabancı otlarla mücadele etmenin temel ön koşul olduğu anlaşımıştır. Bunlarda ilerleme sağlandıktan sonra tane rengi (kırmızı içinde) standartlara dahil edilmelidir.

\section{Kaynaklar}

Anonim, 2004. Extract from the gazette of India part II. section 3, sub-section (I) appearing on page nos. 680-714. http://agmarknet.nic.in/pgrad.htm (Erişim tarihi: 26.09.2013)

Anonim, 2007. Mercimek besin değerleri. http://www.almanalfoods.com/template/pulsessyria.htm (Erişim tarihi: 26.09.2013)

Anonim, 2008a. TS 143 mercimek (kabuklu iç) standardının revizyonuna ilişkin dış ticarette standardizasyon tebliği Resmi Gazete, $\quad 30 \quad$ Mayıs, 2008, sayı: 26891.http://www.resmigazete.gov .tr/main.aspx?home=http://www.resmigazete.g ov.tr/eskiler/2008/05/20080530.htm\&main=htt p://www.resmigazete.gov.tr/eskiler/2008/05/20 080530.htm (Erişim tarihi: 26.09.2013)

Anonim, 2008b. United States Standards for Lentils. http://www.gipsa.usda.gov/fgis/standar ds/lentils.pdf (Erişim tarihi: 26.09.2013)
Anonim, 2010. Yemeklik baklagil hastalık ve zararlıları. http://www.battalgazigth.gov.tr/news file/39240BC5-9CCF-4C21-AA24-

27B4F35D55F6.pdf (Erişim tarihi: 26.09.2013)

Anonim, 2012a. Hububat sektör raporu. http://www.tmo.gov.tr/Upload/Document/raporl ar/HububatSektorRaporu2012.pdf (Erişim tarihi: 26.09.2013)

Anonim, 2012b. Kuru baklagiller. www.tuik.gov.tr/PrelstatistikTablo.do?istab_id= 57 (Erişim tarihi: 26.09.2013)

Anonim, 2013a. Mercimekte tebeşirleşme etmenleri.http://www.tarimziraat.com/hastalik ve_zararlilar/sebze_zararlilari/mercimeklerde_t ebesirlesme_etmenleri/ (Erişim tarihi: 26.09.2013)

Anonim, 2013b. Mercimekte yabancı ot ilacı. http://www.oncatarim.com/herbisitler.i43.prado suit-100-sl (Erişim tarihi: 26.09.2013)

Anonim, 2013c. Mercimek (L. culinaris Medik.) tarlalarında yabancı otlar. http://www.tarimkutuphanesi.com/MERCIMEK _(Lens_culinaris_Medik.) TARLALARINDA YABANCIOTLAR 00566.h tml (Erişim tarihi: 26.09.2013)

Anonim, 2013d. Lentils classes and grades. http://www.grainscanada.gc.ca (Erişim tarihi: 26.09.2013)

Anonim, 2013e. Mercimek samanı besin değerleri. http://samansatisi.com/mercimek-samani.html (Erişim: 26/09/2013)

Coşkuner Y. ve Karababa E., 1998. Türkiye'de mercimek üretim potansiyeli ve işleme teknolojisi. Gıda 23(3):201-203

Özberk, İ., Atlı, A., Özberk, F.,Yücel, A., 2006 The effect of Lygus bug (Exolygus pratensis L.) on marketing price of red lentils in Anatolia, Turkey Crop Protection 25 (2006) 1227-1230

Uzun A. , 1992. Güneydoğu Anadolu Bölgesi'nde mercimek (Lens esculenta Moench) tarlalarında sorun olan dar ve geniş yapraklı yabancı otlara karşı ilaç denemesi. Zirai Mücadele Araştırma Yıllığı, Cilt 20-21, sayfa 227, Diyarbakır

Williams, P.C., Erskine ,W., and Singh,U.,1993. Lentil processing. Lens Newsletter 20 (1)3-13

Zel M., 1974. Doğu ve Güneydoğu Anadolu Bölgesi'nde mercimek tarlalarında mevcut yabancı ot çeşitleri üzerine survey çalışması. Zirai Mücadele Araştırma Yılığı, Cilt 8, sayfa: 80 , Diyarbakır 